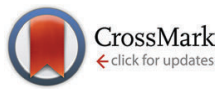

Cite this: Phys. Chem. Chem. Phys., 2016, 18, 19433

Received 9th May 2016 Accepted 23rd June 2016

DOI: $10.1039 / c 6 c p 03129 c$

www.rsc.org/pccp

\title{
Facile modulation of optical properties of octagold clusters through the control of ligand-mediated interactions $\dagger$
}

\begin{abstract}
Mitsuhiro Iwasaki, ${ }^{a}$ Naoki Kobayashi, ${ }^{a}$ Yukatsu Shichibu ${ }^{a b}$ and Katsuaki Konishi*ab
In the recent development of structurally defined ligand-stabilized gold clusters, it has been revealed that not only the inorganic units but also the surrounding organic ligands substantially affect their electronic/optical properties. In this work, a series of core + exo type $\mathrm{Au}_{8}$ clusters decorated by dppp $\left(\mathrm{Ph}_{2} \mathrm{P}\left(\mathrm{CH}_{2}\right)_{3} \mathrm{PPh}_{2}\right)$ and arylthiolate ligands $\left(\left[\mathrm{Au}_{8}(\mathrm{dppp})_{4}(\mathrm{SR})_{2}\right]^{2+}, \mathbf{1 - 5}\right)$ were synthesized, and their optical properties were studied in order to gain insights into the perturbation effects of the organic ligands. 1-5 showed visible absorption and photoluminescence emission bands at longer wavelengths compared to their chloro- and acetylide-modified analogues, suggesting the contribution of weak non-bonding interactions of the $\mathrm{Au}$ framework with the ligand heteroatoms. Upon acid treatment, 2- and 4-pyridinethiolate clusters ( $R=P y, 2$ and 4) showed larger red shifts of the absorption and emission bands than the 3-pyridyl isomer (3), implying the involvement of the resonance structures of the SPy units. On the other hand, all regioisomers (2-4) showed large photoluminescence enhancements upon pyridine protonation. X-ray crystallographic and NMR analyses of $\mathbf{4}$ and its protonated form (4') showed that the electron-deficient pyridinium rings of $\mathbf{4}^{\prime}$ form $\pi$-stacks with neighbouring phenyl groups of dppp, suggesting that the orientation of the surface aromatics is a plausible factor governing the emission efficiency. These observations provide examples of successful modulation of optical properties of small gold clusters through the electronic and/or steric perturbation by the proximal organic ligands, highlighting the importance of the ligand design in the fine tuning of cluster properties directed for optical chemosensors and luminescent materials.
\end{abstract}

\section{Introduction}

There is considerable current interest in the unique properties of structurally defined ligand-stabilized gold clusters with nuclearity of less than $100 .{ }^{1}$ One of the prominent features of such cluster species is their molecule-like behaviour offering structured visible electronic absorptions, which are closely related to the nature of their intrinsic electronic structures

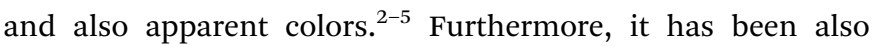
reported that some clusters are photoluminescence active, ${ }^{6-13}$ which sometimes extend to the near-IR region, ${ }^{14-18}$ expanding the scope of the potential application of this class of compounds. ${ }^{19-21}$

\footnotetext{
${ }^{a}$ Graduate School of Environmental Science, Hokkaido University, North 10 West 5, Sapporo 060-0810, Japan

${ }^{b}$ Faculty of Environmental Earth Science, Hokkaido University, North 10 West 5 , Sapporo 060-0810, Japan. E-mail: konishi@ees.hokudai.ac.jp;

Fax: +81 11 7064538; Tel: +81117064538

$\dagger$ Electronic supplementary information (ESI) available: Details of synthesis and characterisation data, and supporting spectroscopic and crystal data. CCDC 1477150 for $4 \cdot\left(\mathrm{NO}_{3}\right)_{2}$ and 1477151 for $\mathbf{4}^{\prime} \cdot\left(\mathrm{BF}_{4}\right)_{4}$. For ESI and crystallographic data in CIF or other electronic format see DOI: $10.1039 / \mathrm{c} 6 \mathrm{cp} 03129 \mathrm{c}$
}

Recent advances in the crystal structure determination have enabled precise structure-based inspection of the factors affecting their electronic and optical properties, which revealed that the overall trends are mostly governed by the nuclearity and geometries of inorganic moieties..$^{5,9,22-25}$ The surrounding organic ligands used to keep up the cluster entity have been believed to be virtually electronically inert, but the recent experimental results showed that they sometimes cause substantial perturbation on the cluster's electronic properties. ${ }^{26-29}$ For example, it is reported that the ligand moieties of $\mathrm{Au}_{25}(\mathrm{SR})_{18}$ affect the geometry of the cluster framework causing the alteration of the electronic properties, which was further interpreted by a theoretical study. ${ }^{30}$ The electronic effect of the ligand moieties is an important feature for developing designer clusters with specific functions, but the nature of the role of the organic units is still elusive.

Recently, we reported the site-specific introduction of organic functionality on the core + exo type octagold cluster in the synthesis of $\left[\mathrm{Au}_{8}(\mathrm{dppp})_{4}\left(\mathrm{C} \equiv \mathrm{CR}^{\prime}\right)_{2}\right]^{2+}$, which accommodates four diphosphine $\left(\mathrm{dppp}=\mathrm{Ph}_{2} \mathrm{P}\left(\mathrm{CH}_{2}\right)_{3} \mathrm{PPh}_{2}\right)$ and two acetylide ligands. ${ }^{31}$ We also provided an example of the modulation of the optical properties through $\pi$-conjugated units attached to 
the gold cluster. For example, pyridylethynyl-modified clusters $\left(\mathrm{R}^{\prime}=\right.$ Py) showed protonation-induced absorption and photoluminescence responses, which were critically dependent on the relative position of the pyridine nitrogen atom. Especially, the photoluminescence of the 3-pyridyl isomer was negligibly affected by the protonation event, which is in contrast to the significant quenching observed for the 2- and 4-pyridyl isomers. From these observations, we have proposed that the resonance structures of $\pi$-conjugated ligand units critically affect the electronic structure of the cluster moieties.

In the present paper, we used analogous $\mathrm{Au}_{8}$ clusters with arylthiolate ligands $\left(\left[\mathrm{Au}_{8}(\mathrm{dppp})_{4}(\mathrm{SR})_{2}\right]^{2+}, \mathbf{1 - 5}\right)$ to obtain insights into the factors affecting the electronic transitions of the $\mathrm{Au}_{8}$ moiety. First, we demonstrate that weak non-bonding interactions involving the ligand heteroatoms have substantial effects on the clusters' electronic properties through the study on a series of core + exo type $\mathrm{Au}_{8}$ clusters with different anionic ligands. We also investigated the optical response of the pyridinethiolate (SPy)-modified clusters $(\mathrm{R}=\mathrm{Py})$ to the pyridine protonation events, and show that the optical absorption (excitation) and photoluminescence emission energies were critically dependent on the $\pi$-resonance structures of the SPy units, but the emission intensity (quantum yield) was not. Based on the ${ }^{1} \mathrm{H}$ NMR investigations coupled with X-ray structural analyses we show that the emission intensities are mainly governed by the structural factors rather than the electronic factors of the ligand environment. Although there are several recent reports of gold clusters that show liganddependent electronic properties, ${ }^{26-28}$ the present approach is advantageous since the overall geometrical feature of the gold skeleton $\left(\mathrm{Au}_{8}\right)$ is essentially preserved, which allows the inspection of the subtle effects of the ligand environments through the systematic studies for clusters with a variety of ligands.

\section{Results}

\section{Synthesis and structures of thiolate-modified $\mathrm{Au}_{8}$ clusters (1-5)}

We have previously reported that the reaction of $\left[\mathrm{Au}_{8}(\mathrm{dppp})_{4}\right]^{2+}$ with acetylide anion occurs smoothly accompanied with the oxidative rearrangement of the cluster geometry, leading to the selective formation of the diacetylide $\mathrm{Au}_{8}$ clusters with a core + exo type geometry. ${ }^{31}$ Likewise, dithiolate $\mathrm{Au}_{8}$ clusters $\left[\mathrm{Au}_{8}(\mathrm{dppp})_{4}(\mathrm{SR})_{2}\right]^{2+}(\mathbf{1 - 5})$ were easily obtained via nucleophilic reactions of the corresponding thiols with $\left[\mathrm{Au}_{8}(\mathrm{dppp})_{4}\right]^{2+}$ (Fig. 1a). The produced cationic clusters were isolated as nitrate salts, which were unambiguously characterised by electrospray ionization (ESI) mass spectrometry, ${ }^{1} \mathrm{H}$ and ${ }^{31} \mathrm{P}$ NMR spectroscopy, and elemental analyses (see the ESI $\dagger$ ). X-ray crystal structural analysis was successfully performed for the 4-pyridinethiolatemodified cluster $\left(\mathbf{4} \cdot\left(\mathrm{NO}_{3}\right)_{2}\right)$, which confirmed the core + exo type $\mathrm{Au}_{8}$ unit composed of a bitetrahedral $\mathrm{Au}_{6}$ core and two attached gold atoms at the exo positions (Fig. 1b). The geometrical features (i.e., bond lengths/angles) of the gold framework of 4 were almost similar to those of the dichloro- (6) and di(arylethynyl)derivatives such as 7 (Tables S3-S5, ESI $\dagger$ ). The Au-Au bond (a)

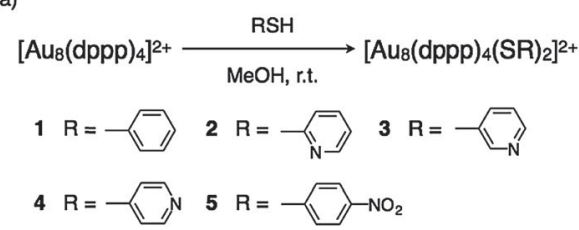

(b)

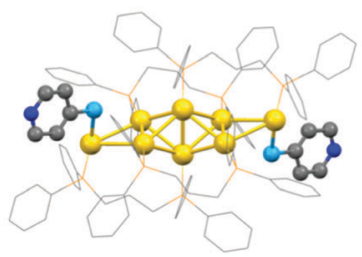

Fig. 1 (a) Synthesis scheme for $\left[\mathrm{Au}_{8}(\mathrm{dppp})_{4}(\mathrm{SR})_{2}\right]^{2+}(\mathbf{1 - 5})$ and (b) crystal structure of $\mathbf{4}$ with hydrogen atoms omitted for clarity.

distances in the polyhedral core are in the range of 2.629-2.866 $\AA$, which are comparable to those of $6(2.648-2.872 \AA)^{6}$ and 7 (2.628-2.865 $\AA$ ). ${ }^{31}$ The $\mathrm{Au}_{\text {exo }}-\mathrm{Au}_{\text {edge }}$ distances of $4(3.010-3.150 \AA)$ are slightly longer than those of 6 (2.970-3.072 $\AA$ ) and 7 (2.931-3.019 ̊).

The crystal structure of $\mathbf{4}$ also reveals that the thiolate ligands are linked to the gold unit in a monodentate manner. This is in contrast to the binding patterns found in conventional all-thiolate protected clusters, ${ }^{1}$ whose thiolate ligands mostly have multidentate character to form protecting staple motifs around a polyhedral gold core. The two S-substituents are oriented along the long axis of the prolate-shaped gold units, reflecting the $\mathrm{sp}^{3}$ character of the $\mathrm{S}$ atom and steric hindrance with the neighbouring $\mathrm{P}-\mathrm{Ph}$ groups. The molecular structure in the solid state appears to be virtually retained in solution. The ${ }^{31} \mathrm{P}$ NMR spectrum of $4 \cdot\left(\mathrm{NO}_{3}\right)_{2}$ in $\mathrm{CD}_{3} \mathrm{OD} / \mathrm{CD}_{2} \mathrm{Cl}_{2}$ showed signals at $36.1,50.5$ and $54.4 \mathrm{ppm}$ with an integrated intensity ratio of $1: 2: 1$ (Fig. S4c, ESI $\dagger$ ), which is in agreement with the X-ray structure. Such ${ }^{31} \mathrm{P}$ NMR patterns were also observed for the other thiolate-modified clusters (see the ESI $\dagger$ ).

\section{Basic optical properties}

In previous papers, we have shown that chloro- (6) and acetylide(7) modified $\mathrm{Au}_{8}$ clusters exhibit single absorption bands at $\sim 510 \mathrm{~nm},{ }^{6,31}$ which are assigned to the intracluster metal-tometal transition. ${ }^{24}$ The thiolate-modified $\mathrm{Au}_{8}$ clusters (1-5) also showed similar isolated visible bands, but they were observed at substantially long wavelengths (Table 1 and Fig. S5, ESI $\dagger$ ). For instance, 4. $\left(\mathrm{NO}_{3}\right)_{2}$ in methanol showed a band at $526 \mathrm{~nm}$ (Fig. 2a(i), solid line), which was red-shifted by $\sim 15 \mathrm{~nm}$ from 6. $\left(\mathrm{PF}_{6}\right)_{2}$. As mentioned, $\mathrm{S}$ atoms in the thiolate ligand tend to bind with multiple gold atoms, as found in the staple motifs in the all-thiolate protected clusters. Accordingly, in the present case, the $\mathrm{S}$ atom may interact weakly with the proximal gold atoms on the exo-bridged edges of the bitetrahedron, as schematically illustrated in Fig. 3a. In fact, the crystal structure of $4 \cdot\left(\mathrm{NO}_{3}\right)_{2}$ gave the shortest $\mathrm{S}-\mathrm{Au}_{\text {edge }}$ distances of $3.166 \AA$, which were evidently shorter than the sum of the van der Waals radii (3.46 $\AA$ ). It should be also noted that the 2-pyridinethiolate-modified cluster (2) gave a 
Table 1 Absorption and photoluminescence spectral data of $\left[A u_{8}(\mathrm{dppp})_{4} \mathrm{X}_{2}\right]^{2+}(1-7)^{a}$

\begin{tabular}{|c|c|c|c|}
\hline & & Absorption & Photoluminescence \\
\hline Cluster & $\mathrm{X}$ & $\lambda / \mathrm{nm}$ & $\lambda / \mathrm{nm}$ \\
\hline $\mathbf{1} \cdot\left(\mathrm{NO}_{3}\right)_{2}$ & $\mathrm{SPh}$ & 530 & 621 \\
\hline $2 \cdot\left(\mathrm{NO}_{3}\right)_{2}$ & S(2-Py) & 518 & 604 \\
\hline $3 \cdot\left(\mathrm{NO}_{3}\right)_{2}$ & S(3-Py) & 528 & 612 \\
\hline $4 \cdot\left(\mathrm{NO}_{3}\right)_{2}$ & S(4-Py) & 526 & 609 \\
\hline $5 \cdot\left(\mathrm{NO}_{3}\right)_{2}$ & $\mathrm{SC}_{6} \mathrm{H}_{4}\left(4-\mathrm{NO}_{2}\right)$ & 531 & 623 \\
\hline 6. $\left(\mathrm{PF}_{6}\right)_{2}{ }^{b}$ & $\mathrm{Cl}$ & 509 & 600 \\
\hline $7 \cdot\left(\mathrm{NO}_{3}\right)_{2}{ }^{c}$ & $\mathrm{C} \equiv \mathrm{CPh}$ & 509 & 580 \\
\hline
\end{tabular}

(a)

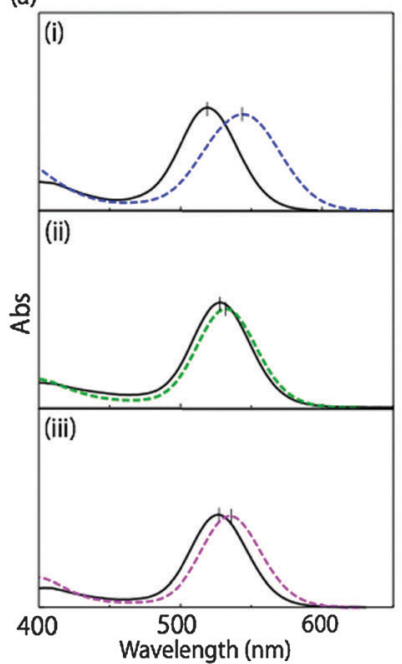

(b)

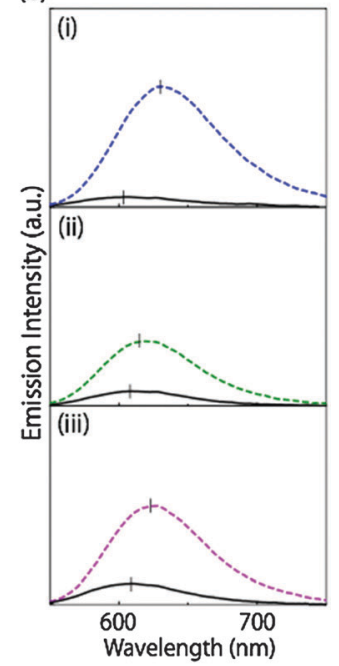

Fig. 2 (a) Absorption and (b) photoluminescence spectra of (i) 2. $\left(\mathrm{NO}_{3}\right)_{2}$ $\left(\lambda_{\mathrm{ex}}=531 \mathrm{~nm}\right)$, (ii) $3 \cdot\left(\mathrm{NO}_{3}\right)_{2}\left(\lambda_{\mathrm{ex}}=533 \mathrm{~nm}\right)$ and (iii) $4 \cdot\left(\mathrm{NO}_{3}\right)_{2}\left(\lambda_{\mathrm{ex}}=532 \mathrm{~nm}\right)$ in $\mathrm{MeOH}(2 \mu \mathrm{M})$ at $20{ }^{\circ} \mathrm{C}$ before (solid) and after (dashed) the addition of $\mathrm{MeSO}_{3} \mathrm{H}$ (600 molar equiv.). The excitation wavelengths were chosen so as to have the same absorbance before and after the addition of $\mathrm{MeSO}_{3} \mathrm{H}$.

(a)

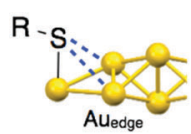

(b)

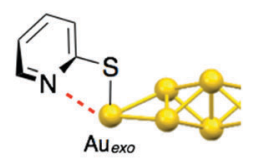

Fig. 3 Schematic illustration of possible weak interactions between the gold unit and the neighbouring (a) $\mathrm{S}$ or (b) $\mathrm{N}$ atoms.

band at a shorter wavelength $(518 \mathrm{~nm})$ than the 3- and 4-regioisomers (528 and $526 \mathrm{~nm}$, respectively), suggesting the involvement of the weak $\mathrm{N}-\mathrm{Au}_{\text {exo }}$ interaction (Fig. $3 \mathrm{~b}$ ). In this regard, the ${ }^{31} \mathrm{P}$ NMR signal due to the $\mathrm{P}$ atoms attached to the $\mathrm{Au}_{\text {exo }}$ atom (P3, Fig. S4, ESI $\dagger$ ) was observed at $35.2 \mathrm{ppm}$ for $2 \cdot\left(\mathrm{NO}_{3}\right)_{2}$, which is evidently upfield from those of $3 \cdot\left(\mathrm{NO}_{3}\right)_{2}$ and $\mathbf{4} \cdot\left(\mathrm{NO}_{3}\right)_{2}$ (36.0 and $36.1 \mathrm{ppm}$, respectively), whereas the signals due to the other $\mathrm{P}$ atoms (P1 and P2) were observed at almost identical positions (Fig. S4, $\mathrm{ESI} \dagger)$. Although the structural information in solution is limited at the present stage, the above observations imply that the weak

interaction with the proximal heteroatoms electronically affects the electronic structures of the $\mathrm{Au}_{8}$ moiety.

We have also reported previously that $\mathrm{Au}_{8}$ clusters (6 and 7) exhibit photoluminescence at $\sim 580 \mathrm{~nm}$ upon excitation of the HOMO-LUMO transition. ${ }^{6,31}$ Likewise, the thiolate-modified clusters (1-5) showed similar photoluminescence but the emission bands were observed at longer wavelengths, which are in accordance with the red shifts of the absorption bands (Table 1).

\section{Protonation-induced optical responses of 2-4}

The absorption and photoluminescence spectra of the pyridinethiolate (SPy)-modified clusters (2-4) upon addition of methanesulfonic acid were recorded in methanol at $20{ }^{\circ} \mathrm{C}$ and the data are summarized in Table 1. Fig. 2a shows the absorption spectral changes, which indicate that all isomers exhibit some red shifts. Isosbestic points were observed in the titration profiles of all three isomers (Fig. S6, ESI $\dagger$ ), suggesting that the spectral changes essentially resulted from simple pyridine protonation events. Indeed, the spectra reverted to the original forms upon neutralization by treatment with 2-ethanolamine. Further, the benzenethiolate-modified cluster (1) showed no spectral changes under similar conditions (Table 2, entry 1), excluding the possibility of the involvement of the direct protonation of the gold units or S atoms.

It should be noted that the degree of the protonationinduced red shifts varied significantly with the $\mathrm{N}$ position of the pyridine functionality (Fig. $2 \mathrm{a}$ and Table 2, entries 2-4). Similar trends have been reported in the optical responses of pyridylethynyl-ligated $\mathrm{Au}_{8}$ clusters $\left(\left[\mathrm{Au}_{8}(\mathrm{dppp})_{4}(\mathrm{C} \equiv \mathrm{CPy})_{2}\right]^{2+}\right),{ }^{31}$ for which the critical effects of the resonance structures of the $\pi$-conjugated ligand moiety were implicated. Also in the present thiolate system, the electronic effect of the $\pi$-resonance structure appeared to be a plausible main factor responsible for the observed spectral shifts. For instance, in the protonated form of the 3-pyridyl isomer (3), the location of the positive charge should be limited only within the pyridine ring (Fig. 4b). Consequently, the protonation would cause only minor electronic effects on the $\mathrm{Au}_{8}$ unit, and accordingly, the observed shifts of the absorption and emission bands were very small (Fig. 2a(ii); Table 2, entry 3). On the other hand, when 2 or 4 is protonated, a resonance contributor with the $\mathrm{C}=\mathrm{S}^{+}-\mathrm{Au}$ fragment should be generated (Fig. 4a). The positive charge and the conjugated $\pi$-system attached to the exo Au atom would substantially affect the electronic structures of the $\mathrm{Au}_{8}$ unit, which may lead to large red shifts. Among the three isomers (2-4), the 2-pyridyl isomer (2) showed especially large band shifts $(25 \mathrm{~nm})$. As mentioned in the above section, the $\mathrm{N}$ atom of the free-base form of 2 likely interacts with the exo gold atom (Fig. 3b). The protonation would result in the breaking of such weak interaction, which may also contribute to the relatively large responses.

The perturbation effects coupled with the $\pi$-resonance structures of the SPy ligand were also observed in the shifts of the photoluminescence emission bands, where 2 and 4 showed definitely larger red shifts (25 and $16 \mathrm{~nm}$, respectively) than 3 (6 nm) (Fig. 2b and Table 2). In contrast, such trends were not found for the emission intensities. The protonated forms of the three isomers 
Table 2 Absorption and photoluminescence responses of 1-4 to $\mathrm{MeSO}_{3} \mathrm{H}$

\begin{tabular}{|c|c|c|c|c|c|c|c|c|c|}
\hline & & $\mathrm{X}$ & \multicolumn{3}{|c|}{ Absorption } & \multicolumn{4}{|c|}{ Photoluminescence } \\
\hline 1 & $\mathbf{1} \cdot\left(\mathrm{NO}_{3}\right)_{2}$ & $\mathrm{SPh}$ & 530 & 530 & 0 & 621 & 621 & 0 & 1.0 \\
\hline 3 & $3 \cdot\left(\mathrm{NO}_{3}\right)_{2}$ & S(3-Py) & 528 & 532 & 4 & 612 & 618 & 6 & 4.7 \\
\hline 4 & $4 \cdot\left(\mathrm{NO}_{3}\right)_{2}$ & S(4-Py) & 526 & 535 & 9 & 609 & 625 & 16 & 4.5 \\
\hline
\end{tabular}

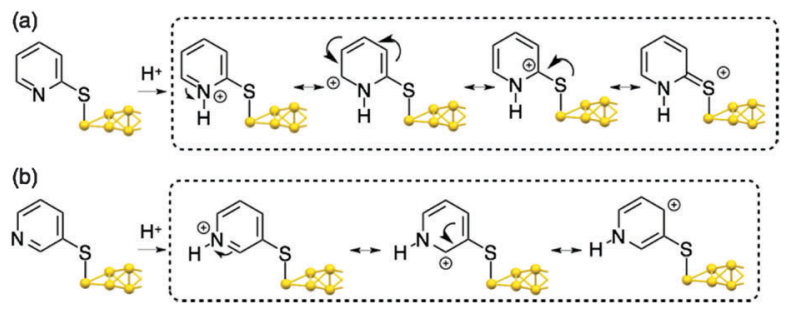

Fig. 4 Possible resonance contributors of the protonated forms of (a) 2 and (b) 3

all showed much higher emission intensities than the free-base forms by factors of 4-10 (Table 2). This is in contrast to the trend observed for $\left(\left[\mathrm{Au}_{8}(\mathrm{dppp})_{4}(\mathrm{C} \equiv \mathrm{CPy})_{2}\right]^{2+}\right)^{31}$ upon protonation; 2- and 4-pyridyl isomers showed considerable losses of the emission (quenching), while the 3-isomer was virtually inactive. The comparable increases of the emission intensities of $\mathbf{3}$ and $\mathbf{4}$ upon pyridine protonation indicated that the resonance structures of the SPy unit are not involved in the 'turn-on' photoluminescence response. So we have to consider different mechanisms in order to account for this behaviour.

\section{Structural changes upon pyridine protonation}

To gain insights into the photoluminescence profiles of the pyridinethiolated clusters, we investigated the structures by X-ray crystallography and solution ${ }^{1} \mathrm{H}$ and ${ }^{31} \mathrm{P}$ NMR spectroscopy. Fig. 5 shows the crystal structures of $\mathbf{4}$ and its protonated form $\left(\mathbf{4}^{\prime}\right)$. Although some minor differences were found for some $\mathrm{Au}-\mathrm{Au}$ and $\mathrm{S}-\mathrm{Au}_{\text {edge }}$ distances (Table S3, ESI $\dagger$ ), the basic core + exo features of the gold units were almost the same. In contrast, distinct differences were found in the ligand environments especially for the orientation of the aromatic rings. In the freebase form, the pyridine rings and the neighbouring $\mathrm{Ph}$ group (Ph2 in Fig. 5a) of the dppp ligands (4) take a herringbone-like orientation (Fig. 5b). On the other hand, a slightly tilted $\pi$-stack was found in the corresponding aromatic rings in the protonated form $\left(\mathbf{4}^{\prime}\right)$. The shortest $\mathrm{C}-\mathrm{C}$ contact distance was $3.36 \AA$, which is almost close to the sum of the van der Waals radii of carbon atoms. According to the literature ${ }^{32-34} \pi-\pi$ interaction can be considered when the shortest $\mathrm{C}-\mathrm{C}$ distance is less than $3.8 \AA$. Therefore, the $\pi$-stack in $\mathbf{4}^{\prime}$ suggests the presence of $\pi-\pi$ interaction between the pyridinium unit and the proximal $\mathrm{Ph}$ ring. This is reasonable considering that the protonation event would enhance the electron-deficient character of the pyridine ring, which facilitates the $\pi-\pi$ interaction. ${ }^{32}$

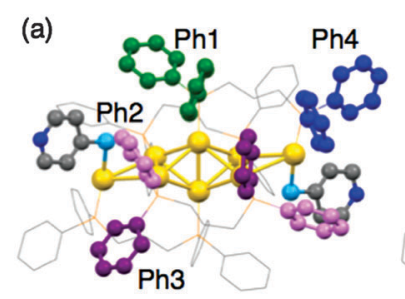

(b)
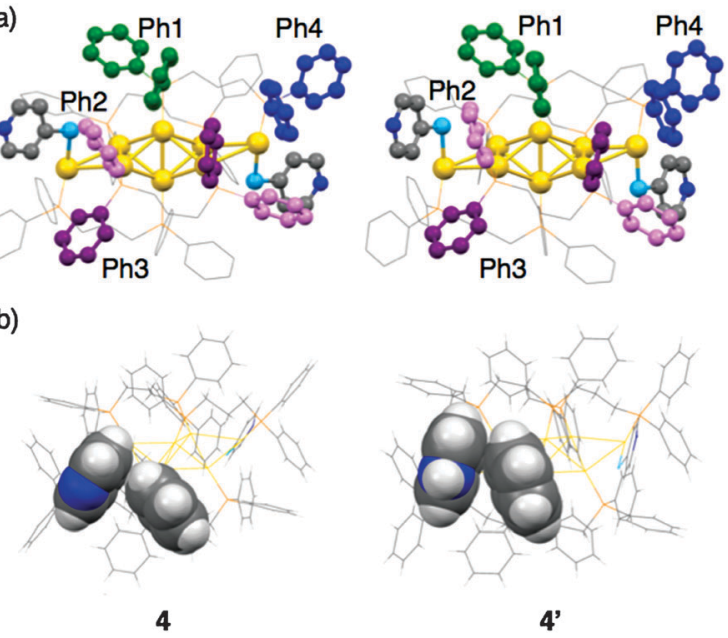

Fig. 5 (a) Crystal structures of cationic moieties of $4 \cdot\left(\mathrm{NO}_{3}\right)_{2}$ and $\mathbf{4}^{\prime} \cdot\left(\mathrm{BF}_{4}\right)_{4}$. (b) Structures with the orientation of a pyridine ring and the neighbouring Ph2 ring highlighted.

Based on these observations, we next recorded the ${ }^{1} \mathrm{H}$ and ${ }^{31} \mathrm{P}$ NMR spectra of $4 \cdot\left(\mathrm{NO}_{3}\right)_{2}$ in the presence and absence of methanesulfonic acid. The aromatic region of the ${ }^{1} \mathrm{H}$ NMR spectrum of $4 \cdot\left(\mathrm{NO}_{3}\right)_{2}$ at $293 \mathrm{~K}$ (Fig. 6a) reveals signals due to the pyridyl protons and four sets of $\mathrm{Ph}$ groups (Ph1, Ph2, $\mathrm{Ph} 3$, and $\mathrm{Ph} 4)$, which were assigned with the aid of the ${ }^{1} \mathrm{H}^{-1} \mathrm{H}$ COSY spectrum (Table S6 and Fig. S7, ESI $\dagger$ ). Variable temperature studies showed that the broadened signals of the $\mathrm{Ph} 2$ and $\mathrm{Ph} 3$ protons are due to the slow exchange under the NMR time scale (Fig. S8, ESI $\dagger$ ). Fig. 6b shows the spectrum of the protonated form $\left(\mathbf{4}^{\prime}\right)$, where the pyridine protons underwent downfield shifts reflecting the decrease of the electron density of the aromatic ring. If the pyridine protonation does not affect the orientation and structures of the phosphine ligand moieties, the Ph signals would appear at the same positions. However, the signals due to some phenyl groups showed notable shifts upon pyridine protonation. Especially, the $o$-protons of $\mathrm{Ph} 2$ nearby the pyridine ring showed a marked upfield shift $(\Delta \delta=$ $0.12 \mathrm{ppm}$ ). Definite shifts were also observed for some protons of Ph1 and $\mathrm{Ph} 2$, whereas some other $\mathrm{Ph}$ protons (such as of $\mathrm{Ph} 4)$ remained almost unchanged. Therefore, the protonation event caused the orientation change of the $\mathrm{Ph} 2$ and adjacent $\mathrm{Ph} 1$ units. Accordingly, in the ${ }^{31} \mathrm{P}$ NMR at $293 \mathrm{~K}$, the $\mathrm{P}$ atoms attached to the Ph1 (P1, Fig. S9, ESI $\dagger$ ) and $\mathrm{Ph} 2 / \mathrm{Ph} 3$ rings (P2) showed downfield shifts upon pyridine protonation. 


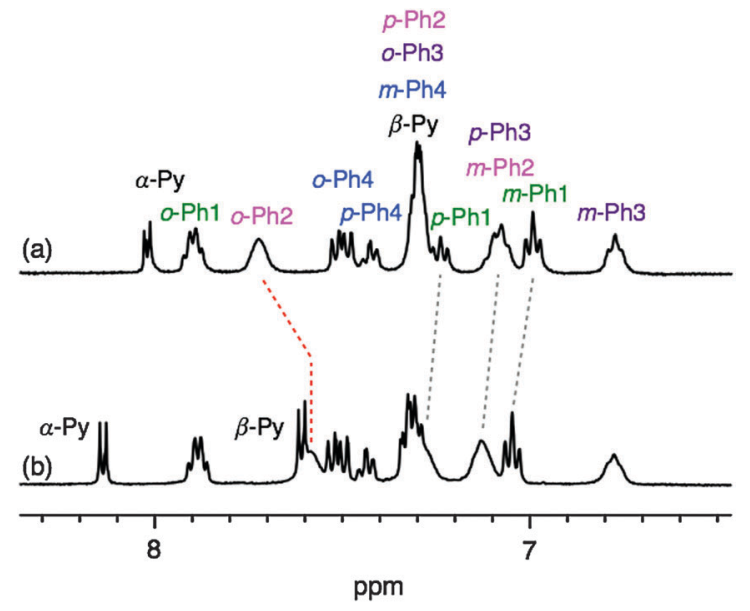

Fig. 6 Aromatic region of the ${ }^{1} \mathrm{H}$ NMR spectra of 4 in $\mathrm{CD}_{3} \mathrm{OD}(1.5 \mathrm{mM})$ at $293 \mathrm{~K}$ (a) before and (b) after the addition of $\mathrm{MeSO}_{3} \mathrm{H}$ (2 molar eq.). For the numbering of the Ph groups, see Fig. $5 \mathrm{a}$.

The above different NMR profiles of $\mathbf{4}$ and its protonated form $\left(\mathbf{4}^{\prime}\right)$ seem to reflect the conformational difference found in the crystalline state. As mentioned, the crystal structure of $\mathbf{4}^{\prime}$ revealed that the $\mathrm{Ph} 2$ units favour to form $\pi$-stacked complexes with the electron-deficient pyridinium moiety. Such interligand $\pi-\pi$ interaction arising from the electron-deficient character would also occur in solution, which may be associated with the observed shifts of the NMR signals. Indeed, in the ${ }^{1} \mathrm{H}$ NMR spectrum of 5 , which bears electron-withdrawing nitro substituents on the thiolate ligand of $\mathbf{1}$, the $o$-Ph2 protons appeared evidently upfield ( $\delta=7.63$ ) from those of $\mathbf{1}(\delta=7.76)$ (Fig. S10, ESI $\dagger$ ). This is very similar to the trend found in the spectra of $\mathbf{4}$ and $\mathbf{4}^{\prime}$ (Fig. 6). Thus, the orientation of the surface aromatic arrays can be altered by switching of the weak interligand interaction through the control of $\pi$-electron density, which may lead to the observed emission enhancements.

\section{Discussion}

Direct electronic effects of the ligands on the cluster properties

Through the investigations on the series of core + exo type $\mathrm{Au}_{8}$ clusters, we have shown that the visible absorption and photoluminescence emission energies significantly vary with the characters of anionic ligands attached to the exo gold atoms. It is well established that the basic absorption spectral patterns of small gold clusters are uniquely dependent on the geometry of the gold frameworks. For the core + exo type $\mathrm{Au}_{8}$ clusters, the isolated absorption band at 500-550 $\mathrm{nm}$ has been assigned to the HOMO-LUMO transition. ${ }^{24}$ If the ligand moieties do not cause any influences, the absorption bands of the $\mathrm{Au}_{8}$ clusters would appear at the same energy, irrespective of the ligand characters. Therefore, the observed variation of the energies of the absorption and emission bands should reflect the perturbation effects of the proximal chemical environments on the HOMO/LUMO.

For the factors affecting the HOMO/LUMO features, geometrical structures of the gold frameworks and electronic perturbations of the organic ligand moieties are considered. Inspections of the X-ray crystallographic structures available $\left(\mathbf{4}, \mathbf{4}^{\prime}, \mathbf{6}, 7\right)$ showed minor differences in the geometrical parameters of the $\mathrm{Au}_{8}$ frameworks (e.g., Au-Au lengths/angles, symmetry) (Tables S3-S5, ESI $\dagger$ ). However, there is no clear trend to support the correlation of the cluster geometry and the absorption and emission energies. For instance, the $\mathrm{Au}_{\mathrm{exo}}-\mathrm{Au}_{\text {edge }}$ distances of $\mathbf{4}^{\prime}$ and $\mathbf{6}$ were almost similar to each other (Table S3, ESI $\dagger$ ), but the absorption band positions were much different (Tables 1 and 2). Although we have to take account of the difference of the structures in solution and packed crystals, electronic rather than geometrical factors of the ligands are likely to affect the absorption and photoluminescence band energies. Thus, for the thiolate-modified clusters (1-5), the weak interaction of the $\mathrm{S}$ atom and $\mathrm{Au}_{\text {edge }}$ atoms may result in the formation of new orbitals. Among them, the 2-pyridinethiolated cluster (2) shows a band at an exceptionally short wavelength $(518 \mathrm{~nm})$ when compared with the other thiolate-modified clusters (526-531 nm), which may be correlated with the additional interaction of the pyridine $\mathrm{N}$ atom with $\mathrm{Au}_{\text {exo }}$, as illustrated in Fig. 3.

Meanwhile, the absorption and emission bands of 2 and 4 considerably red-shifted upon pyridine protonation, for which a critical role of the $\pi$-resonance structures of the SPy units was suggested (Fig. 4a). As mentioned, a resonance contributor with a positive charge on the $S$ atom (e.g., $\mathbf{4}^{\prime} \mathbf{b}$, Fig. 7) is considered primarily responsible for the red shifts of the absorption/ emission bands. The generation of such a resonance structure would lead to the cleavage of the $\mathrm{S} \cdot \mathrm{Au}_{\mathrm{edge}}$ weak interaction in the free base form. Indeed, in the crystal structures, the shortest $\mathrm{S}-\mathrm{Au}_{\text {edge }}$ distances of $\mathbf{4}^{\prime}$ (3.437 $\AA$ ) were much longer than those of 4 (3.166 ̊) (Table S3, ESI $\dagger$ ), and were comparable to the sum of van der Waals radii (3.46 ̊). Thus, upon protonation, they would behave similarly to the non-thiolate type clusters (6, 7, Table 2), and would show blue shifts of the absorption band to $\sim 510 \mathrm{~nm}$. However, 2 and 4 both showed opposite trends (red shifts) (Table 2 and Fig. 2). From these observations, the electronic coupling of the $\mathrm{Au}_{8}$ unit with a $\pi$-resonance structure of the $\mathrm{SPy}^{+}$units of 2 or 4 may be involved in the observed red shifts (Fig. 7). The difference in the red shifts between 2 and 4 (Table 2, entries 2 and 4 ) suggests that the degree of the cluster- $\pi$ interaction depends on the probability to take the effective resonance form having a positively charged $\mathrm{S}$ atom $\left(\right.$ e.g., $\left.\mathbf{4}^{\prime} \mathbf{b}\right)$. It should be also noted that $\left[\mathrm{Au}_{8}(\mathrm{dppp})_{4}(\mathrm{C} \equiv \mathrm{CPy})_{2}\right]^{2+}$ exhibits similar red shifts when the protonation induces an extended charged resonance structure. ${ }^{31}$ Therefore, the electronic coupling between the gold

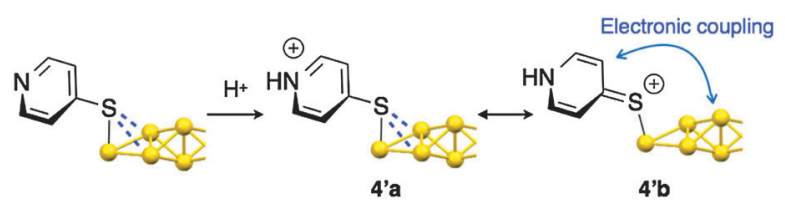

Fig. 7 Schematics of the protonation of 4 to $4^{\prime}$. The formation of a resonance contributor of $\mathbf{4}^{\prime}\left(\mathbf{4}^{\prime} \mathbf{b}\right.$, right) accompanies the cleavage of the $\mathrm{Au}-\mathrm{S}$ interactions and the generation of cluster $-\pi$ interaction. 
unit and the $\pi$-system appears to be a general phenomenon, which will expand the scope of cluster compounds. Such cluster- $\pi$ electronic interactions have been recently reported in an alkynyl-ligated $\mathrm{Au}_{13}$ cluster system. ${ }^{29}$

From these considerations, it is clear that ligand moieties can cause direct perturbation effects on the electronic properties of the $\mathrm{Au}_{8}$ framework through weak coordinative non-bonding interactions with heteroatoms ( $\mathrm{S}$ or $\mathrm{N}$ ) and/or electronic coupling with the $\pi$-system. These electronic effects are likely the results of the involvement of the atomic orbitals of the heteroatoms or $\pi$-system in the molecular orbitals (e.g., HOMO and LUMO), so the difference of the absorption/emission energies may reflect the degree of the contribution of the ligand-derived moieties to the molecular orbitals. Further theoretical studies are required for the comprehensive understanding of the electronic perturbations of the ligands. Nevertheless, the above findings demonstrate the utility of the organic ligand environments for the fine-tuning of the electronic structures/properties of cluster compounds.

\section{Mechanism of the emission enhancements}

On the other hand, the emission efficiencies of the SPy-modified clusters (2-4) were notably enhanced by protonation. In this regard, Jin et al. have reported the photoluminescence properties of a series of $\left[\mathrm{Au}_{25}(\mathrm{SR})_{18}\right]^{-}$clusters with different $\mathrm{R}$ substituents. ${ }^{35}$ They claimed that the increase of the electron-donating character of $\mathrm{R}$ leads to the emission enhancement as a result of the improvement of the charge-transfer efficiency. However, such a mechanism seems unlikely in the present case, since the pyridine protonation should enhance the electron-withdrawing character of the Py unit. Further, comparable emission enhancements of $\mathbf{3}$ and $\mathbf{4}$, whose protonated forms should have different resonance schemes (Fig. 4), imply that the $\pi$-resonance structures of the ligand moieties were not primarily important. Therefore, it is likely that the structural factors, rather than the direct electronic effects, are predominantly responsible for the observed emission enhancements. As mentioned in the crystallographic and solution NMR studies of $\mathbf{4}$ and its protonated form $\left(\mathbf{4}^{\prime}\right)$, the protonation-induced increase of the electron deficient character of the pyridine unit led to the $\pi$-stack formation with the neighbouring Ph group, which may affect the emission intensity. Accordingly, 4-nitrobenzenethiolate-modified cluster (5), whose NMR behaviours suggest the formation of similar $\pi$-stacks due to the electron-withdrawing $\mathrm{NO}_{2}$ groups (Fig. S9, ESI $\dagger$ ), showed approximately four times larger emission than the simple benzenethiolate-modified cluster (1) (Fig. S11, ESI $\dagger$ ). Therefore, the $\pi$-stack formation, which leads to the alteration of the orientation of surface aromatic environments, may be associated with the observed emission enhancements.

In this regard, recent papers on the ligand effects of emissive metal complexes showed that high emission intensities are obtained when the steric hindrances of the ligand environments are increased. ${ }^{36,37}$ It is claimed that the small structural difference between the ground and excited states, which arises from the enhanced rigidity of the hindered complexes, leads to the decrease of the probability of the non-radiative path. We think that such a steric-based mechanism can reasonably account for our observation. Thus, the $\pi$-stack formation upon pyridine protonation may rigidify the encapsulating environment to suppress the conformational freedom. Consequently, the structural change upon excitation would be restricted, leading to high emission intensity. Thus, the emission efficiency of the present $\mathrm{Au}_{8}$ cluster system may be controlled by the switching of weak non-bonding interligand interaction around the inorganic moiety.

\section{Conclusions}

It has been well established that the electronic/optical properties of small gold clusters are mainly governed by the nuclearity and geometrical structures of the central gold cluster units. In this paper, we definitively show that the surrounding organic environments also affect the optical properties of small Au clusters through the electronic and steric perturbation effects. We demonstrated that the weak $\mathrm{Au} \cdot \mathrm{S} / \mathrm{Au} \cdots \mathrm{N}$ non-bonding interaction or the electronic coupling with the $\pi$-resonance contributors of the attached ligands causes the shift of the optical absorption band associated with the intracluster metalto-metal transition. We also suggested that the $\pi$-stack formation in the peripheral aromatic ring environment, which was induced by local chemical events at the ligand moiety, could lead to the increase of emission efficiency. These results clearly indicate that electronic and steric factors of the surface organic ligand units are able to cause perturbation effects on the optical/electronic properties of ligand-protected clusters, offering versatile toolboxes for the fine tuning of the clusters' electronic properties towards designer clusters.

\section{Acknowledgements}

This work was partially supported by the MEXT/JSPS grant-inaids (24350063 for K. K. and 24750001 for Y. S.).

\section{Notes and references}

1 R. Jin, Nanoscale, 2015, 7, 1549-1565.

2 P. Maity, S. Xie, M. Yamauchi and T. Tsukuda, Nanoscale, 2012, 4, 4027-4037.

3 Y. Pei and X. C. Zeng, Nanoscale, 2012, 4, 4054-4072.

4 T. Tsukuda, Bull. Chem. Soc. Jpn., 2012, 85, 151-168.

5 K. Konishi, Struct. Bonding, 2014, 161, 49-86.

6 Y. Kamei, Y. Shichibu and K. Konishi, Angew. Chem., Int. Ed., 2011, 50, 7442-7445.

7 A. Ghosh, T. Udayabhaskararao and T. Pradeep, J. Phys. Chem. Lett., 2012, 3, 1997-2002.

8 Z. Luo, X. Yuan, Y. Yu, Q. Zhang, D. T. Leong, J. Y. Lee and J. Xie, J. Am. Chem. Soc., 2012, 134, 16662-16670.

9 Y. Shichibu, M. Zhang, Y. Kamei and K. Konishi, J. Am. Chem. Soc., 2014, 136, 12892-12895.

10 K. Pyo, V. D. Thanthirige, K. Kwak, P. Pandurangan, G. Ramakrishna and D. Lee, J. Am. Chem. Soc., 2015, 137, 8244-8250. 
11 N. Goswami, Q. Yao, Z. Luo, J. Li, T. Chen and J. Xie, J. Phys. Chem. Lett., 2016, 7, 962-975.

12 X. Kang, S. Wang, Y. Song, S. Jin, G. Sun, H. Yu and M. Zhu, Angew. Chem., Int. Ed., 2016, 55, 3611-3614.

13 Y. Yu, Z. Luo, D. M. Chevrier, D. T. Leong, P. Zhang, D. E. Jiang and J. Xie, J. Am. Chem. Soc., 2014, 136, 1246-1249.

14 Y. Shichibu and K. Konishi, Small, 2010, 6, 1216-1220.

15 S. Park and D. Lee, Langmuir, 2012, 28, 7049-7054.

16 Y. Shichibu, K. Suzuki and K. Konishi, Nanoscale, 2012, 4, 4125-4129.

17 A. Mathew, E. Varghese, S. Choudhury, S. K. Pal and T. Pradeep, Nanoscale, 2015, 7, 14305-14315.

18 T. Wang, D. Wang, J. W. Padelford, J. Jiang and G. Wang, J. Am. Chem. Soc., 2016, 138, 6380-6383.

19 S. Wang, X. Meng, A. Das, T. Li, Y. Song, T. Cao, X. Zhu, M. Zhu and R. Jin, Angew. Chem., Int. Ed., 2014, 53, 2376-2380.

20 L. Shang, N. Azadfar, F. Stockmar, W. Send, V. Trouillet, M. Bruns, D. Gerthsen and G. U. Nienhaus, Small, 2011, 7, 2614-2620.

21 L. Shang, S. Dong and G. U. Nienhaus, Nano Today, 2011, 6, 401-418.

22 H. Qian, M. Zhu, Z. Wu and R. Jin, Acc. Chem. Res., 2012, 45, 1470-1479.

23 Y. Shichibu, Y. Kamei and K. Konishi, Chem. Commun., 2012, 48, 7559-7561.

24 Y. Shichibu and K. Konishi, Inorg. Chem., 2013, 52, 6570-6575.
25 C. Zeng, Y. Chen, K. Iida, K. Nobusada, K. Kirschbaum, K. J. Lambright and R. Jin, J. Am. Chem. Soc., 2016, 138, 3950-3953.

26 Y. Negishi, U. Kamimura, M. Ide and M. Hirayama, Nanoscale, 2012, 4, 4263-4268.

27 A. Das, C. Liu, C. Zeng, G. Li, T. Li, N. L. Rosi and R. Jin, J. Phys. Chem. A, 2014, 118, 8264-8269.

28 Y. Song, J. Zhong, S. Yang, S. Wang, T. Cao, J. Zhang, P. Li, D. Hu, Y. Pei and M. Zhu, Nanoscale, 2014, 6, 13977-13985.

29 M. Sugiuchi, Y. Shichibu, T. Nakanishi, Y. Hasegawa and K. Konishi, Chem. Commun., 2015, 51, 13519-13522.

30 A. Tlahuice-Flores, R. L. Whetten and M. Jose-Yacaman, J. Phys. Chem. C, 2013, 117, 20867-20875.

31 N. Kobayashi, Y. Kamei, Y. Shichibu and K. Konishi, J. Am. Chem. Soc., 2013, 135, 16078-16081.

32 C. Janiak, J. Chem. Soc., Dalton Trans., 2000, 3885-3896.

33 H. G. Kim, C.-W. Lee, S. Yun, B. H. Hong, Y.-O. Kim, D. Kim, H. Ihm, J. W. Lee, E. C. Lee, P. Tarakeshwar, S.-M. Park and K. S. Kim, Org. Lett., 2002, 4, 3971-3974.

34 H. W. Roesky and M. Andruh, Coord. Chem. Rev., 2003, 236, 91-119.

35 Z. Wu and R. Jin, Nano Lett., 2010, 10, 2568-2573.

36 S. Igawa, M. Hashimoto, I. Kawata, M. Hoshino and M. Osawa, Inorg. Chem., 2012, 51, 5805-5813.

37 C. E. McCusker and F. N. Castellano, Inorg. Chem., 2013, 52, 8114-8120. 